\title{
Author Correction: Diagnosis, grading and management of toxicities from immunotherapies in children, adolescents and young adults with cancer
}

Dristhi Ragoonanan (D), Sajad J. Khazal (D, Hisham Abdel-Azim, David McCall (D, Branko Cuglievan, Francesco Paolo Tambaro, Ali Haider Ahmad, Courtney M. Rowan, Cristina Gutierrez, Keri Schadler, Shulin Li, Matteo Di Nardo, Linda Chi, Alison M. Gulbis, Basirat Shoberu, Maria E. Mireles, Jennifer McArthur, Neena Kapoor, Jeffrey Miller, Julie C. Fitzgerald (D), Priti Tewari, Demetrios Petropoulos, Jonathan B. Gill, Christine N. Duncan, Leslie E. Lehmann, Sangeeta Hingorani, Joseph R. Angelo, Rita D. Swinford, Marie E. Steiner, Fiorela N. Hernandez Tejada, Paul L. Martin, Jeffery Auletta, Sung Won Choi (D), Rajinder Bajwa (D), Natalie Dailey Garnes (D, Partow Kebriaei, Katayoun Rezvani, William G. Wierda, Sattva S. Neelapu D, Elizabeth J. Shpall, Selim Corbacioglu and Kris M. Mahadeo (D)

Correction to: Nature Reviews Clinical Oncology https://doi.org/10.1038/s41571-021-00474-4, published online 19 February 2021.

In the original version of this Consensus Statement, the name of the author Christine N. Duncan was incorrectly written as Christine N. Duncun. In addition, Fig. 1 contained errors regarding the criteria to grade cytokine-release syndrome (CRS). "Hypotension not requiring vasopressors" has now been corrected to "hypotension requiring one vasopressor \pm vasopressin" for grade 3 CRS and "hypotension requiring multiple vasopressors, not including vasopressin" for grade 4 CRS. The affiliations and Fig. 1 have been corrected in the HTML and PDF versions of the manuscript.

https://doi.org/10.1038/s41571-021-00497-x I Published online 17 March 2021

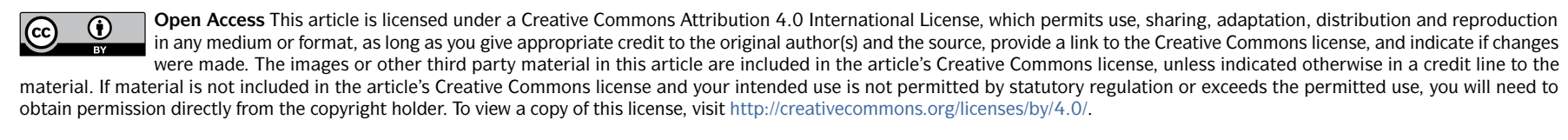

(c) The Author(s) 2021

\section{Author Correction: Anaplastic glioma: benefit of temozolomide clarified}

\section{Diana Romero}

Correction to: Nature Reviews Clinical Oncology https://doi.org/10.1038/s41571-021-00527-8, published online 25 May 2021.

In the originally published article, the $95 \%$ confidence interval for patients with IDH-mutant disease with and without concurrent temozolomide was incorrect: $0.35-0.67$. Instead, this confidence interval is $0.58-1.10$. These values have been corrected in the HTML and PDF versions of the article.

https://doi.org/10.1038/s41571-021-00531-y I Published online 10 June 2021

(c) Springer Nature Limited 2021 